\title{
ORALIDADE E LETRAMENTO NA SALA DE AULA
}

Clarice Saboia Madureira*

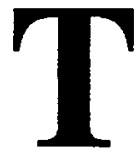

em-se como um fato indiscutivel que a escola básica é o lugar onde o falante aprende a forma escrita de seu idioma e, principalmente por meio dela, tem acesso a conhecimentos considerados básicos para seu bom desempenho na sociedade. Mesmo a prática dos alunos mais tenros da pré-escola já visa em grande parte objetivos ligados à aquisição da escrita. E através de todo o processo educacional observa-se, nas aulas de lingua materna, a preocupação dominante ou mesmo exclusiva com a capacitação dos aprendizes no uso da escrita. Aliás, a aquisição da escrita e seu desenvolvimento - na produção e na recepção de textos escritos - têm sido os temas recorrentes das pesquisas de lingüistica aplicada ao ensino de lingua materna. ${ }^{1}$ Enfim, não é preciso exemplificar muito: todos os envolvidos no processo conhecem a realidade. A concepção do ensino de língua materna parece mesmo se resumir à idéia de formar leitores e produtores de textos escritos. Não é por acaso que os cursos superiores que formam professores de linguas se intitulam Cursos de Letras. 2

Apesar de mobilizar tantos esforços, são freqüentes as queixas de que o sistema educacional não está tendo muito sucesso na formação de usuários da escrita. As reclamações procedem de todos os lados: os aprendizes se dizem enfadados com as aulas de língua materna (é comum ouvir-se dos estudantes a afirmação de que as aulas de Português são monótonas e improdutivas), os

* Universidade Federal do Parana.

${ }^{1}$ Ver, por exemplo, quadro descrito em KLEIMAN (1992).

$2 \mathrm{Na}$ formação de professores de linguas estrangeiras há uma grande preocupação com a oralidade, mas aqui me interessa a formação do professor de Português para falantes nativos. 
professores se sentem frustrados e a sociedade convive com o triste complexo de incapacidade diante da cultura letrada. E quanto à formação de falantes seguros e eficazes? $O$ quadro não é muito diferente, embora não seja comumente objeto de reflexão. Talvez pelo fato de terem sido abolidas as provas orais, na escola não se pensa muito no desempenho oral dos alunos, embora seja comum ouvir dos professores comentários sobre as limitações do desempenho oral dos jovens.

Este quadro lamentável tem, certamente, várias causas, algumas das quais são freqüentemente discutidas. Mas há, me parece, alguns pontos que não têm sido devidamente examinados. Entre estes estão a excessiva ênfase na escrita e o descaso com a oralidade, marcas de uma cultura ainda estigmatizada pelo analfabetismo de muitos. Na verdade, trata-se de dois lados de uma mesma moeda que circula na sociedade e tem na escola sua matriz, com efeitos nocivos sobre a prática escolar, que, justamente, deveria favorecer o desenvolvimento da competência comunicativa dos alunos.

O impacto da escrita sobre as sociedades humanas é por demais conhecido. A utilização de um sistema de escrita ć considerada a própria linha divisória entre um estágio pré-histórico e um histórico. ${ }^{3}$ A partir da invenção da escrita ampliaram-se, sem dúvida, as possibilidades de acumular conhecimentos, de modo que as sociedades que utilizaram algum sistema de registro de linguagem num meio material passaram a se desenvolver tecnologicamente em ritmo inigualado pelas sociedades ágrafas. Isto é um fato incgável.

Não é de admirar, portanto, que a posse de tal invento tenha sido venerada c interpretada como sinal de predileção dos deuses ou de capacidade intelectual superior dos povos que a obtiveram. A possibilidade de registrar ganhos, tratados, impostos a receber e grandes feitos bélicos de forma mais duradoura somou-se aos instrumentos de poder dos governantes e criou a classe dos escribas-sacerdotes, depositários do saber constituido de suas épocas. Além disso, a possibilidade de deixar mensagens gravadas para o futuro atendia aos desejos grandiosos de atingir alguma forma de imortalidade.

$\mathrm{Na}$ história da decifração de escritas antigas contada em Doblhoffer (1962), encontram-se inúmeros excmplos do cnorme valor dado pelos poderosos à escrita como forma de se projetar para o futuro, como forma de se perpetuar na lembrança das gerações seguintes. Vejamos um desses exemplos.

Em 1836, o inglês Henry Creswicke Rawlinson, dublê de consultor militar e apaixonado pesquisador de inscrições antigas, "descobriu" e decifrou inscrições babilônicas de dois mil e quinhentos anos que, juntamente com um

${ }^{3}$ A teoria da Grande Divisão, que considera a oposição entre as sociedades letradas e as ágrafas como uma dicotomia, é contestada por vários autores. Goody (1990), por exemplo, considera tal visão uma simplificação injustificada de um complexo processo de aquisição de várias tecnologias que podem afetar em graus diferentes os modos de comunicação. 
conjunto de esculturas em baixo-relevo, adomam os rochedos de Behistun, na Pérsia. A decifração do texto trilingüe, trabalho de perseverança e erudição, constituiu um feito notável, mas mais notável ainda me parece o trabalho de coleta. As inscriçōes e as esculturas encontram-se a mais de cem metros do chão, num rochedo de paredes lisas e ingremes. O próprio Rawlinson descreveu minuciosamente as agruras por que passou para chegar aos textos. Ao narrar como copiou o tex to em persa, por exemplo, escreveu:

Mal conseguimos encostar-nos à parede da rocha, enquanto seguramos o cademo com a mão esquerda e o lápis com a direita. Foi em tal posição que copiei todos os textos da parte superior, e de tal modo me absorvi no trabalho que me esqueci inteiramente do perigo. É muito mais difícil chegar ao nicho que contém a parte crítica. (apud DOBLHOFFR, 1962, p.116)

Imagine-se, então, o que custou cm esforço humano a gravaçāo dessas rochas! Mas qual cra o conteúdo de mensagem tão penosamente gravada? Em três linguas, em três sistemas de escrita diferentes, nas encostas rochosas e escarpadas de Behistum, Dario, Rei dos Persas, diz ao futuro que ć o rei dos reis, que é poderoso, que é o aquemênida e que sua familia é nobre há muito tempo. E conclui:

Anuncia o rei Darajawauch:

Tu que no futuro

verás esta inscrição

por mim mandada gravar na pedra,

estas figuras de homens,

não destruas nada! E enquanto viveres,

trata de conservá-las intatas. (apud DOBLHOFFer, 1962,

p.123)

Herrenschmidt (1995) ressalta, é verdade, que o império persa, por sua extensão e também por seguir uma velha prática mesopotâmica, produziu textos que se caracterizavam pelo multilingüismo e por falarem sempre em nome do rei. Mas $\mathrm{em}$ quase todas as histórias de decifração de escritas antigas relatadas em Doblhoffer (1962) aparecem textos do mesmo teor. Aliás, um dos métodos adotados pelos decifradores cra o de isolar primeiramente os nomes dos reis, que podiam ser facilmente reconhecidos por serem as seqüèncias mais freqüen- 
tes, e muitas vezes assinaladas com algum recurso gráfico como, por exemplo, uma linha de contorno que os encapsulava.

A intima ligação entre a escrita e o poder - secular, religioso ou aquele obtido através do monopólio do conhecimento - é enfocada de maneira sucinta e clara em Gnerre (1987). Para as sociedades em que alguns dominaram ou dominam um sistema de escrita e para todas aquelas que entraram em contato com escritas utilizadas por outros, o uso deste instrumento apresentou-se como um recurso dos poderosos. Vale lembrar aqui que desde os mais remotos registros de escrita até hoje se passaram cerca de seis mil anos. Durante todo esse periodo, a familiaridade com a escrita tem sido um privilégio de poucos nas culturas em que ocorre. A idéia de educação universal é recente e incipiente. A inda são muitas as linguas sem escrita $e$, nas sociedades com escrita, são muitos os falantes que vivem à margem da vida letrada. A verdade é que a capacidade de registrar linguagem por meio de algum tipo de escrita tem sido, ao longo desses sessenta séculos, um atributo de membros de classes dominantes.

Não deve causar espanto, por essas razões, que a escrita tenha moldado uma forma de linguagem e uma concepção de linguagem. A questão da padronização lingüística, a preocupação com a gramática — no sentido original de "arte de escrever" - decorreram da prática da escrita. Por um lado, é preciso admitir que o alcance espacial e temporal do escrito, por oposição à efemeridade da fala, cria a necessidade de uma certa padronização que lhe garante eficácia e aguça a consciĉncia metalingüística dos usuários do sistema. Mas, por outro, é preciso reconhecer também que um instrumento tão poderoso - e para alguns sagrado - tem suscitado a utilização de uma linguagem especial, às vezes até secreta. E ć por isso que escrever não tem sido apenas saber utilizar um sistema de sinais gráficos que reflete a fala, mas também - ou mesmo principalmente - saber empregar a linguagem dos iniciados. O contato das classes mais favorecidas com a forma padrão de uma língua se dá não só no sentido de que são elas que a definem, a partir de seu dialeto. Num processo circular, também passam, numa scgunda etapa, a pautar sua fala mais formal pelos padrōes estabelecidos para a escrita $c$ a ver a língua através do filtro metalingüístico estabelecido pela prática da escrita.

Esta transferência não admitida conscientemente tem deixado nas teorias modernas marcas que só recentemente começam a ser examinadas. Scholes e Willis (1995) observam que "a ciência da linguagem tem tratado a língua e seus usuários, ao menos neste último século, como se a ortografia nunca tivesse sido inventada, limitando a língua à fala, e até mesmo igualando-as”. A afirmação vale tanto para Sapir, para quem a língua se define como "um sistema de símbolos..., antes de tudo auditivos", quanto para Bloomfield, para quem "a escrita não é a língua, é meramente um modo de registrá-la através de sinais visiveis", e Chomsky, com seu "falante-ouvinte ideal”. E por não considerar as 
complexas relaçōes que se estabelecem entre a escrita e a fala, sobretudo a aguda consciência metalingüistica criada no falante por sua inserção em uma cultura letrada, o lingüista não se apercebe da influência de sua experiência letrada na sua concepção de linguagem. Aplicando testes a grupos de falantes de inglês adultos letrados e não-letrados, Scholes e Willis (1995) chegam à conclusão de que a lingüistica tem atribuído à competência do falante - no sentido técnico do termo - relaçōes que fazem parte apenas do conhecimento dos letrados.

Householder (1971) propôs mesmo que a fonologia gerativa assumisse as formas escritas do inglês como formas fonológicas subjacentes, para dar conta da competência dos falantes letrados. Para iniciar a apresentação de seus argumentos, recorre com muita graça à história de Tarzan, o menino criado por macacos, que aprende sozinho a ler em inglès, e mais tarde a falar e ler em francês, e só depois disso vem a conhecer a forma oral do inglês. Householder aponta que esse percurso insólito jamais espanta os leitores porque na verdade corresponde à ordem das coisas que aos leigos parece intuitivamente lógica, ou mesmo ideal. Tarzan evitou assim o caminho tortuoso que percorremos: "aprendemos primeiro a falar, e depois a ler e escrever, após o que precisamos voltar atrás e corrigir todos os erros que cometemos por termos aprendido primeiro a falar" (p. 248, tradução minha, destaque do texto original).

Os efeitos da ideologia letrada certamente se fazem sentir no sistema educacional com mais força ainda. Bernstein (1964) argumentou que o mau desempenho escolar dos filhos das classes trabalhadoras poderia ser explicado pclo deficit lingüistico que apresentam $\mathrm{cm}$ comparação com os filhos das classes mais altas. As caracteristicas que, segundo Bernstein, distinguem as duas variantes - por ele chamadas de código restrito e código elaborado, respectivamente - foram posteriormente relacionadas por outros autores com as diferenças que opõem a fala pré-letramento à fala pós-letramento (Brown, 1981), c o discurso não-planejado ao discurso plancjado (Ochs, 1982). Ou seja, as crianças provenientes de classes tradicionalmente letradas aprendem - para certas finalidades - a "falar" a cscrita. Bernstein não encontrou apoio entre os lingüistas, mas não se pode negar que sua descrição do código elaborado corresponde aos textos veiculados e valorizados pela escola.

Vejamos como Kato (1990) sintetiza e interpreta as diferenças apontadas por Bernstein entre a linguagem dos alunos provenientes das classes trabalhadoras $\mathrm{e}$ os alunos provenientes das classes média $\mathrm{e}$ alta.

A definiçāo lingüistica dos dois códigos pode ser vista no quadro abaixo: 
Quadro 1 - Diferenças lingüisticas entre código restrito $e$ código elaborado.

$\begin{array}{lcc}\begin{array}{l}\text { Varińvel estrutural } \\ \text { número de orações } \\ \text { subordinadas }\end{array} & \text { Código elaborado } & \text { Código restrito } \\ \begin{array}{l}\text { número de locuções } \\ \text { verbais complexas }\end{array} & \text { maior } & \text { menor } \\ \begin{array}{l}\text { uso de passiva } \\ \text { uso de adjetivos }\end{array} & \text { maior } & \text { menor } \\ \text { uso de advérbios } & \text { maior } & \text { menor } \\ \begin{array}{l}\text { uso de pronomes } \\ \text { pessoais }\end{array} & \text { maior } & \text { menor } \\ & \text { maior } & \text { menor } \\ & & \text { menor }\end{array}$

A definição psicológica e a lingüística interessam-nos mais de perto, pois elas poderiam perfeitamente diferenciar a modalidade escrita formal da oral informal.

A definição lingüística, além do mais, leva-nos a crer que o motivo principal dessas diferenças, que Bernstein atribui parcialmente à classe social, pode ser perfeitamente explicada pelo nivel de letramento da comunidade em que a criança está inserida. Assim, crianças de classe humilde, mas de pais letrados, podem revelar um desempenho lingüístico com as características preconizadas para o código elaborado. (p.21-22)

Robinson (1977) apresenta algumas pesquisas que foram feitas na Inglaterra para testar a teoria de Bernstein. Em uma delas, o contraste entre a escrita de rapazes de mesma idade - quinze anos - e de classes sociais diferentes é ilustrado por dois exemplos muito interessantes. Vejamos o que podem nos revelar.

Ensaio de um rapaz de quinze anos, pertencente à classe trabalhadora, sobre

\section{Minha vida daqui a dez anos}

Espero ser um carpinteiro casado e quero viver numa casa moderna e fazer misérias na estrada de Sidcup com uma motocicleta, e também beber no bar local.

Meu passatempo vai ser criar cães e tempo livre dirigindo uma loja de animais de estimação. E vou estar usando a última moda em matéria de roupas. 
Espero que minha vida daqui a dez anos seja feliz, sem preocupação nenhuma e tenho um bom "saudo" atrás de mim. Vou levar uma vida divertida $\mathrm{e}$ feliz. Vou trabalhar duro para conseguir algo neste mundo.

Coisa que não farei na vida é trazer desgraça $\mathrm{e}$ infelicidade à minha familia. (in LAWTON, 1963, p.112)

Ensaio de um rapaz de quinze anos, pertencente à classe média, sobre

\section{Minha vida daqui a dez anos}

Quando olho $\mathrm{em}$ torno de mim e vejo as maravilhas da ciência moderna e todos os novos e fantásticos progressos feitos, sinto uma leve sensação de desânimo. Isto porque começo a me precupar com quem esteja no controle do mundo daqui a dez anos, a máquina ou o homem. Os homens já tèm sido lançados ao redor da Terra em foguetes, $\mathrm{e}$ já estāo construindo máquinas com velocidade cada vez maior que a anterior. Imagino se o mundo nāo estará se transformando num gigantesco manicómio quando eu for dez anos mais velho. Dizem que estaremos dirigindo veículos supersónicos a velocidades fantásticas, com televisores, camas, e até mesmo controles automáticos de direção. Quereremos isso, descjaremos ser govemados pelas máquinas? Bem longe de nós eșarão os tempos $\mathrm{cm}$ que a familia ia a piqueniques, quando numa tarde de domingo estivermos correndo $\mathrm{em}$ amplas auto-estradas, e, apertando um botão, logo teremos a nossa frente um prato de sanduiches prontos. Talvez. pensem que isso seja um tanto improvável, mas se as coisas continuarem como vão, os homens não terão que pensar por si próprios, e nós nos tornaremos uma raça de boçais. Se é isto o que vai acontecer, não há meio de evitá-lo. Os homens dizem que teremos apenas uma ou duas comodidades a mais, e o processo nunca que tem fim. Mas quem é que decide qual deva ser o limite? Ninguém sabe; é apenas um mundo de pessoas, cada qual confiando em que outros farão o que for preciso para impedir que isto aconteça, mas ninguém se atreve a tomar a iniciativa. Estamos condenados. Não há reza capaz de nos salvar agora; nós viramos escravos de grandes monstruosidades ambulantes. Impotentes, nas mãos de algo que ajudamos a criar. Estou preocupado com o que venha a ser "minha vida daqui a dez anos". (in LAWTON, 1968, p.113, apud ROBINSON, 1977 p.161-62). 
Diga-se de passagem que, embora constatasse nos seus dados as diferenças previstas por Bernstein, Lawton não as considerou como indicadoras de deficit, argumentado que poderiam refletir apenas uma questão de escolha. Mas os ensaios reproduzidos acima interessam aqui como exemplos de textos produzidos por dois tipos de alunos. $O$ primeiro é de uma simplicidade ingênua $e$ de uma sinceridade tocante. $\mathrm{O}$ segundo tem já quase todos os ingredientes de uma concepção pomposa do estilo letrado. Qual dos dois agradaria mais a um professor? Posso garantir que para a grande maioria dos professores o segundo exemplo mereceria uma melhor avaliação. O léxico é rico, as construções complexas, a abordagem do tema envereda por preocupações aparentemente sérias. Mas, numa análise mais minuciosa dos fatos, a valorização deste texto se deve ao fato de que o autor demonstra ter o domínio não apenas da escrita em si, mas dos valores estéticos dos letrados. Os professores avaliadores poderão apontar falhas na coesão e na coerência do primeiro texto. Elas existem, é certo, mas apenas a partir da definição dada a esses termos dentro do ponto de vista da tradição letrada. Tudo se passa como se a escrita criasse o texto coeso e coerente, já que a fala é caótica. Essa inversão da ordem das coisas faz lembrar as discussões sobre as cores dos sonhos: "Você sonha em preto $\mathrm{e}$ branco ou $\mathrm{cm}$ cores?" - a distinção criada pelas técnicas da fotogralia passam a ser atribuídas ao inconsciente...

Creio que se possa dizer que o primeiro texto, apesar ou por causa de suas dispersōes, é honesto e direto em relação ao tema. De forma singela o autor expõe seus planos modestos de adolescente. Já o autor do segundo texto opta pelo tema grandioso da relação entre o homem moderno e a tecnologia, repetindo seguramente uma litania que supõe agradar aos receptores. O jovem de quinze anos que se diz tão preocupado com a hipótese de o mundo se transformar "num gigantesco manicômio" parece estar mais preocupado ainda em impressionar um público específico com a profundidade de suas elucubrações. Arrisco mesmo supor que se trata de um daqueles alunos “bem formados” das escolas de classes média e alta: os que aprenderam o jogo do letramento e dominam a retórica valorizada pelas classes letradas, tanto no enfoque do tema quanto na forma que "por coincidência" atende a tơlas as especificações do código elaborado.

A fascinação com as realizações culturais propiciadas pelo domínio da escrita levou mesmo à suposição de que a capacidade de escrever e ler acarretasse mudanças cognitivas notáveis. O tema foi examinado cuidadosamente por estudiosos como Luria, Goody e a dupla Scribner e Cole. Estes últimos, após uma pesquisa extensa detalhadamente reportada e analisada em Scribner e Cole (1981), concluíram que a única mudança significativa observada dizia respeito à capacidade de falar sobre a linguagem. Para chegar a esta conclusão observaram, entrevistaram e testaram - com testes modelares da psicologia cognitiva - membros letrados da etnia Vai, da Libéria. Os Vai oferecem condições 
extraordinárias para um estudo do impacto da escrita, pois possuem desde o início do século passado um silabário próprio que é transmitido informalmente, isto é, sem mediatização de um sistema educacional formal. Portanto, a influência da escrita podia ser testada isoladamente, sem interferência de fatores trazidos pela educação formal. Os resultados que obtiveram, comparando os Vai que utilizavam o silabário sem terem sido expostos à escolarização com outros que haviam passado pelo sistema escolar, revelaram que muitas das mudanças cognitivas atribuidas ao domínio da escrita resultavam do contato com sistemas formais de educação ou de experiências mo-dernizantes, como a de viver num centro urbano.

A conclusão semelhante chegaram Olson, Hildyard e Torrance (1985):

Os efeitos da escrita sobre as mudanças intelectuais e sociais não são de fácil compreensão... É enganoso pensar a escrita em termos de suas conseqüências. $O$ que realmente importa é aquilo que as pessoas fazem com ela, e não o que ela faz com as pessoas. A escrita não produz uma nova maneira de pensar, mas a posse de um registro escrito pode permitir que se faça algo antes impossível: reavaliar, estudar, reinterpretar e assim por diante. De maneira similar, a escrita não provoca a mudança social, a modernização ou a industrialização. Mas ser capaz de ler e escrever pode ser crucial para o desempenho de certos papéis na sociedade industrial, também podendo ser completamente irrelevante para o desempenho de outros papéis em uma sociedade tradicional. A escrita é importante em termos da realização do que possibilita às pessoas: 0 alcance daquilo que objetivam ou a produção de novos objetivos. (apud OLSON e TORRANCE, 1995, p.7)

Sem dúvida, a possibilidade de registrar duradouramente as experiências culturais permite ao indivíduo, assim como às sociedades, uma reflexão cumulativa que é mais difícil e às vezes impossivel sem esse apoio material. O que quero destacar é que ainda se mantém muito viva uma concepção tradicional sobre a escrita, que lhe atribui importância exagerada, a ponto de confundir um instrumento com os objetos que ajuda a produzir, $\mathrm{c}$ mesmo com a capacidade cognitiva dos produtores. O mote de uma campanha de alfabetização oficial de algumas décadas atrás, por exemplo, bradava: "Quem não lê, mal ouve, mal fala, mal vê." Que eu lembre, ninguém contestou. Essa reverência ao letramento pode ter seu lado positivo, na medida em que faz da aquisição da leitura uma meta desejável para os aprendizes, mas tem também aspectos muito negativos. Por se considerar o discurso escrito uma forma superior de linguagem e mesmo de 
organização do pensamento, costuma-se - eu arriscaria dizer que até intencionalmente - afastá-lo da fala, tornando-o ininteligível, secreto, cifrado. Pelas mesmas razões se tem ignorado a importância da oralidade - cada vez maior hoje, com a eficácia das transmissões e gravações de voz - e atribuído mais defeitos que qualidades a suas formas de organização, num equívoco prejudicial ao desenvolvimento da linguagem nas duas modalidades - para nāo mencionar o preconceito que se alimenta contra os não-letrados e as sociedades ágrafas.

Quando se pensa no ensino de língua materna, pensa-se na escrita, na aquisição da leitura, na produção do texto escrito, na formação do leitor, nas oficinas de texto. Mas qual o tempo rescrvado nos programas curriculares para o desenvolvimento da oralidade? Creio que a resposta é "muito pouco" ou "nenhum". Quando se pede aos alunos uma exposição oral, geralmente é apenas o relato de uma texto lido, ou outro pretexto para a prática da leitura e da escrita, objetivo rcal da escolarização. E por que isso acontece? Podemos dizer que isso se deve ao fato de que os alunos já são falantes cficazes, já que são falantes nativos? A meu ver, a escola não se preocupa com o desenvolvimento da cxpressão oral por várias razões, dentre as quais duas se destacam. A primeira decorre do que foi exposto acima: porque se direcionou unicamente para a escrita, implicitamente vista como a única modalidade lingüistica digna de atenção. A segunda decorre da primeira: por se dedicar exclusivamente ao letramento por tanto tempo, não sabe o que nem como trabalhar com a oralidade. Havelock (1995) lamenta o divórcio estabelecido no sistema educacional entre a oralidade e a escrita. Concluo com suas palavras:

Os mecanismos da educação moderna colocam ênfase principal no rápido domínio da leitura c da escrita como preparação para a escola secundária e para a vida adulta. Não deveríamos estar preparados para considerar as possíveis condições impostas ao gerenciamento de nossos sistemas educacionais por meio de nossa herança oral? (...)

Bons leitores surgem a partir de bons falantes (...). (p. 28)

\section{RESUMO}

A tradição letrada deu origem a formas de discurso afastadas da oralidade. Se, por um lado, algumas dessas formas atendem a exigências peculiares da escrita, por outro, há as que servem apenas para marcar o dominio do letramento e garantir o prestigio dos que escrevem. A esse prestigio - herança cultural de alguns milênios - corresponde geralmente uma depreciação da oralidade, o que torna a distância entre as duas modalidades às vezes maior do que o intrinsecamente necessário. No processo educacional, essa 
situação, alicerçada em falsas concepções acerca da escrita e da oralidade, prejudica o desenvolvimento comunicativo dos aprendizes e precisa ser modificada.

Palavras-chave: tradição letrada; ensino da escrita; oralidade.

\section{ABSTRACT}

Literate tradition has given rise to discourse forms that deviate from those of orality. If, on the one hand, some of these forms answer to specific requirements of writing, on the other hand, some of them do no more than attest literate proficiency and secure safer. This prestige - a milenary cultural inheritance - comes generally associated with a depreciative view of orality, making the distance between the two modalities even wider than intrinsically necessary. In the educational process such situation - created by false conceptions about literacy and orality - hinder the communicative development of students and it should be changed.

\section{REFERÊNCIAS BIBLIOGRÁFICAS}

BERNSTEIN, B. “Elaborated and restricted codes". In: GUMPERZ, J. J. e HYMES, D. The etnography of communication. Edição especial de American anthropologist, v. 66, n. $6.2,1964$.

BROWN, G. Teaching the spoken language. In: ASSOCIATION INTERNATIONALE DELINGUISTIC APLIQUÉE. Bruxelas, Proceedings II: Lecture. Encontro de 1981. DOBLHOFFER, E. A maravillosa história das linguas. Trad. Alberto Denis. São Paulo: Ibrasa, 1962.

GNERRE, M. Linguagem, escrita e poder. 2. edição. São Paulo: Martins Fontes, 1987.

GOODY, J. The domestication of the sauge mind. Cambridge: Cambridge University Press, 1977.

HAVELOCK, E. "A equação oralidade-cultura escrita: uma fórmula para a mente moderna". In: OLSON, D. e TORRANCE, N. (Orgs.) Cultura escrita e oralidade. Trad.Valter Lellis Siqueira. São Paulo: Ática, 1995, p. 17-34.

HERRENSCHMIDT, C. “O todo, o enigma e a ilusão”. In: BOTTÉRO, J.; MORRISON, K. et al. Cultura, pensamento e escrita. Trad.Rosa Maria Boaventura e Valter Lellis Siqueira. São Paulo: Ática, 1995, p. 101-39.

HOUSEHOLDER, F. "The primacy of writing". In:

Cambridge: Cambridge University Press, 1971, p. $\overline{244-64 .}$

KATO, M. No mundo da escrita. 3. ed. São Paulo: Ática, 1990.

KLEIMAN, A. "O ensino de linguas no Brasil". In: PASCHOAL, M.S.Z.; CELANI, M. A .A. (Orgs.) Lingüística aplicada. São Paulo: EDUC, 1992, p. 25-36.

OLSON, D.; TORRANCE, N. "Introdução". In: . (Orgs.) Cultura, escrita e oralidade. Trad. Valter Lellis Siqueira. São Paulo: Ática, 1995, p. 7-14. 
ROBINSON, W. P. Linguagem e comportamento social. Trad.de Jamir Martins. São Paulo: Cultrix, 1977.

SCHOLES, R. J.; WILLIS, B. J. “Lingüistas, escrita e intensionalidade no conceito de homem ocidental em McLuhan". In: OLSON, D.; TORRANCE, N. (Orgs.) Cultura, oralidade e escrita. Trad.Valter Lellis Siqueira. São Paulo: Ática, 1995, p. 229-49.

SCRIBNER, S.; COLE, M. The psycholoy of literacy. Cambridge: Harvard University Press, 1981. 